\title{
Desemprego Severo no Meio Rural Brasileiro
}

\author{
Edward Martins Costa $^{1} \mid$ José Eustáquio Ribeiro Vieira Filho ${ }^{2}$ iD \\ ${ }^{1}$ Departamento de Economia Agrícola, Universidade Federal do Ceará. E-mail: edwardcosta@ufc.br \\ ${ }^{2}$ Ministério da Agricultura, Pecuária e Abastecimento. E-mail: jose.eustaquio@agricultura.gov.br
}

\begin{abstract}
RESUMO
Este estudo busca mensurar a probabilidade de o trabalhador rural permanecer por mais de 12 meses desempregado, no Brasil e em suas regiões. Para tanto, utilizou-se a Pesquisa Nacional por Amostra de Domicílios Contínua (PNADC) do $2^{\circ}$ trimestre, a qual contém o suplemento de informações do Programa Bolsa Família (PBF). Ademais, realizou-se a estimação econométrica por meio do modelo Probit. Os resultados mostraram que, ao receber o PBF, ter familiar aposentado e possuir baixo nível de escolaridade, aumenta-se a probabilidade de o trabalhador rural estar no desemprego severo no Brasil. Quanto às regiões rurais, os resultados foram semelhantes aos encontrados no âmbito nacional; entretanto, houve mudança nos sinais das probabilidades, denotando uma heterogeidade no mercado de trabalho rural do país. Essa heterogeneidade ficou evidente entre as regiões Nordeste, onde a agricultura familiar é preponderante, e Centro-Oeste, região reconhecidamente impulsionada pela produção de maior escala. .
\end{abstract}

\section{PALAVRAS-CHAVE}

Desemprego severo, Mercado de trabalho, Regiões rurais, Heterogeneidade

\section{Severe Unemployment in Rural Brazil}

\section{ABSTRACT}

This study seeks to measure the probability for having rural severe unemployment (more than 12 months) in Brazil and its regions. For this purpose, the Pesquisa Nacional por Amostra de Domicílios Continua (PNADC) of the 2nd quarter was used, which contains Bolsa Família Program (PBF) information. In addition, econometric estimation was runned by using a Probit model. The results showed that, when receiving PBF and having a retired family member with low level of education, the likelihood of rural workers being severely unemployed in Brazil increases. For rural regions, the results were like those found at the national level; however, there was a change in probability signs, identifying heterogeneity in the rural labor market. This heterogeneity was clear between the Northeast regions, where family farming is predominant, and the Midwest, a region driven by larger scale production.

\section{KEYWORDS}

Severe unemployment, Labor market, Rural regions, Heterogeneity

CLASSIFICAÇÃO JEL

J08, J21, C25

\section{Introdução}

A estrutura do mercado de trabalho (urbano e rural) mudou significativamente nas últimas décadas, principalmente em decorrência da intensificação tecnológica, o que 
contribuiu, inicialmente, para o êxodo rural (ou migração rural/urbano) e, posteriormente, para o surgimento de novas atividades rurais, agrícolas e não agrícolas, favorecendo a modernização agropecuária (Santos et al., 2010; Buainain e Salvadori D, 2009; Maia e Sakamoto, 2014; Bustos et al., 2016). No entanto, se por um lado essas mudanças ocorrem por conta do aumento da produtividade do trabalho; por outro, surge o desemprego, que constitui grave problema econômico a se enfrentar.

Com a crise econômica e política no Brasil desde 2014, marcada pelo aumento das investigações de corrupção e pelo impeachment presidencial, houve aumento da taxa de desocupação, passando de 6,4\% em 2014 para cerca de 12,4\% em 2019 (IBGE, 2017a). Com o agravamento da crise, a taxa de desemprego no país cresceu, diferentemente do que ocorria no passado. Esse cenário submete os trabalhadores, por receio do desemprego, à aceitação de condições de trabalho com menor remuneração (Pereira et al., 2018).

O meio rural também foi afetado pela crise, principalmente com diminuição do crédito rural $^{1}$, o que prejudicou, indiretamente, a geração de empregos. De acordo com a Pesquisa Nacional por Amostra de Domicílios Contínua (PNADC), realizada pelo IBGE, em 2017, existiam aproximadamente 13,8 milhões de desempregados no Brasil, sendo que $39,5 \%$ estavam a procura de trabalhado por mais 12 meses. Especificamente, no meio rural, cerca de 35,1\% dos trabalhadores desempregados estavam nessa condição, ou seja, pouco mais de um terço (1/3). Vale destacar que o impacto desses fatores se diferencia entre as áreas urbanas e rurais, principalmente devido às características de cada mercado de trabalho e de suas atividades econômicas.

Existe uma ampla discussão dos determinantes do desemprego, sobre como a sua incidência varia de acordo com as características de cada pessoa (gênero, educação, região, idade, ocupação, etc.), tal como destacado em Menezes-Filho e Picchetti (2000); Costa e Cunha (2010); Pereira et al. (2018). Segundo Arruda et al. (2017), tão importante quanto a incidência do desemprego é a duração do desemprego, ou seja, o tempo que os trabalhadores permanecem à procura de emprego. Esse tempo depende das características de cada trabalhador e das dificuldades que cada indivíduo passa ao estar desocupado.

Altas taxas de desemprego, que duram longos períodos, geram o que a literatura chama de "desemprego severo". Essa definição foi inicialmente estudada por Ehrenberg e Smith (2016). Em seguida, Allegretto e Lynch (2010); Mayer (2014); Arruda et al. $(2016,2017)$ observaram que o desemprego severo ocorre na situação em que o indivíduo está desempregado por pelo menos um ano, mas na procura de emprego. Ou seja, o trabalhador não se encontra no estado de desalento ${ }^{2}$.

Em relação ao desemprego severo, estudos recentes, como Arruda et al. (2016,

\footnotetext{
${ }^{1}$ Ver Costa e Vieira Filho (2018); Araujo e Vieira Filho (2018).

${ }^{2} \mathrm{O}$ efeito desalento foi introduzido por Long (1953), sendo composto por um grupo de pessoas desempregadas que não possuía trabalho e nem procurava novas oportunidades nos últimos 30 dias anteriores ao da entrevista, seja por desestímulo do mercado de trabalho, seja por circunstâncias não planejadas.
} 
2017), verificaram as chances de os trabalhadores permanecerem desempregados por mais de 12 meses para a região Nordeste e, posteriormente, para as regiões Sul e Sudeste, ambos antes da crise de 2014. Entretanto, esses estudos não analisaram os determinantes que contribuíram para o desemprego severo no meio rural nessas regiões, mesmo com boa parte da população desempregada, com altas taxas de informalidade e com muitos trabalhadores autônomos.

Nesse contexto, com o intuito de estudar o mercado de trabalho, pretende-se mensurar a probabilidade de ocorrência do desemprego severo no meio rural, assim como nas regiões brasileiras. Adota-se modelagem econométrica capaz de auferir esses resultados. A amostra de dados foi obtida da base estatística da PNADC, que contém informações do Programa Bolsa Família (PBF). O presente artigo busca contribuir para o melhor entendimento do mercado de trabalho no meio rural brasileiro, com destaque aos fatores associados ao desemprego severo, notadamente aos relacionados ao fato de a família ser beneficiada pelo PBF e pela previdência social.

Para tanto, o estudo está dividido em cinco seções, incluindo esta breve introdução. A segunda seção, além de uma revisão da literatura, trata do mercado de trabalho rural e do desemprego no Brasil. A seção três descreve a metodologia, que contempla a base de dados e o modelo econométrico a ser estimado. A seção quatro apresenta as estatísticas descritivas e a análise dos resultados. Por fim, seguem as considerações finais.

\section{Mercado de trabalho rural e desemprego}

De acordo com os dados da PNAD Contínua, que começaram a ser coletados em 2012, até o início do ano de 2014, a média anual de desempregados no Brasil diminuía. No entanto, com a crise política e econômica desde então, o número de desempregados quase dobrou em um período de quatro anos. Os dados mostram que, no ano de 2014, em média, existiam 6,7 milhões de desempregados, estatística que passou para 12,8 milhões, em 2018. O aumento no número de desempregados se deu principalmente no período da recessão, 2014 a 2016, quando o acréscimo foi de 4 milhões de pessoas.

Mesmo com o crescimento da economia após o ano de 2017, o desemprego continuou crescendo. O número de brasileiros trabalhando com carteira assinada diminuiu continuamente desde 2014, aumentando a informalidade. Apesar de a taxa de desemprego não fornecer todas as informações necessárias para uma avaliação detalhada do mercado de trabalho ${ }^{3}$, pode-se considerar esse um indicador relevante, utilizado comumente como termômetro do crescimento econômico (Ramos, 2007).

Ao relacionar o desemprego com a faixa etária, a IBGE (2017b) retrata que o desemprego de longa duração, em que os indivíduos procuraram emprego por cerca de

\footnotetext{
${ }^{3}$ Por exemplo, a quantidade de horas requeridas de trabalho, a remuneração desejada ou a quantidade de indivíduos que desistiram continuar a procura por emprego.
} 
um ano ou mais, expandiu 130\% entre 2014 e 2017. São aproximadamente 5 milhões de pessoas nessa condição, das quais pouco mais da metade $(54,1 \%)$ estava na faixa de 14 a 29 anos de idade. Ao analisar o meio urbano, Mariano et al. (2018) encontraram que os mais jovens são os mais afetados pelo desemprego em tempos de crise. O problema se agrava, já que a entrada dos jovens no mercado de trabalho se dá em funções com menor exigência de experiência e de qualificação. Nesse momento, as vagas de empregos são ocupadas por adultos com ensino superior completo. Depois de certo tempo desempregados, os adultos aceitam trabalhar em funções que remuneram menos.

Para Barbosa Filho e Moura (2015), outro movimento que ocorre no mercado de trabalho em tempos de crise e que também atinge de maneira especial os mais jovens, independente da situação do domicílio (rural ou urbano), é o aumento dos chamados trabalhadores por conta própria. Os dados do IBGE (2017a) mostram que o número de trabalhadores por conta própria aumentou 4,8\% em 2017 e que o rendimento médio foi de R\$ 1.567, um pouco maior do que a remuneração dos trabalhadores sem carteira assinada. Porém, esse rendimento foi $25 \%$ inferior ao dos empregados formais.

O meio rural se destacou por possuir parcela significativa dos desempregados, fenômeno que perdurou até meados da década de 1990. Campolina e Silveira (2008) notaram que, em 1990, a taxa de pessoas desocupadas nas áreas rurais era de 1,6\%, chegando a quase dobrar no ano de 2006, passando a representar $3 \%$ da população economicamente ativa. Da mesma forma, DIEESE (2014), ao considerar dados da IBGE (2013), verificou uma contínua redução das ocupações rurais desde 1985. Em 1995, o número de trabalhadores rurais ocupados era de aproximadamente 17,9 milhões de pessoas, enquanto, em 2013, a população rural no mercado de trabalho foi reduzida para 15,2 milhões. Essa diferença corresponde a uma queda de 15,1\% no número de pessoas ocupadas ao longo de 18 anos. Essa diluição da ocupação rural é corroborada por Maia e Sakamoto (2014). Apesar do dinamismo do setor rural, principalmente nos anos 2000, houve uma significativa redução da ocupação. Para enfrentar o problema da inclusão do trabalhador rural no mercado de trabalho, segundo Balsadi (2001), é preciso ampliar políticas públicas que melhorem a qualificação profissional.

Estudos que analisaram as mudanças ocorridas no mercado de trabalho rural, tais como Tafner (2006); Diniz e Silveira (2008); Campolina e Silveira (2008); DIEESE (2014); Junior e Bacha (2016), relacionaram o desemprego ao aumento das ocupações não agrícolas, o que afetou a oferta de empregos e o perfil dos trabalhadores. Nesse sentido, na visão de Campolina e Silveira (2008), o crescimento das ocupações não agrícolas foi consequência do constante processo de urbanização do meio rural, com o transbordamento das cidades e a integração dos mercados de trabalho, apresentando convergência dos indicadores sociodemográficos entre o urbano e o rural.

Por um lado, de acordo com Maia e Sakamoto (2014), o setor agropecuário tem um 
papel importante na composição da renda do país e o mercado de trabalho rural é afetado pela dinâmica das atividades desenvolvidas nesse meio. Assim, a produtividade agropecuária depende não somente da quantidade de trabalhadores ocupados, mas também da acumulação de capital desses trabalhadores. Ainda segundo os autores, a ocupação agrícola diminuiu nas últimas décadas, chegando a uma redução de aproximadamente de 3,6 milhões de ocupações entre os anos de 2004 e 2014.

Por outro lado, para Buainain e Dedecca (2010), além da queda do emprego em decorrência do surgimento de atividades não agrícolas no meio rural, houve uma redução no número de trabalhadores com remuneração em ocupações agrícolas, acompanhada por um aumento em atividades para o próprio consumo, apesar da evolução do número de trabalhadores com carteira assinada, decorrente do ganho de produtividade no meio rural. Os autores ainda comentam que o Programa Nacional de Fortalecimento da Agricultura Familiar (PRONAF), instituído em 1996, colaborou para o aumento de trabalhadores para o próprio consumo, fato também encontrado por Maia e Sakamoto (2014). Outro ponto importante para a diminuição de trabalhadores no setor agropecuário, de acordo com Buainain e Dedecca (2010), foram os programas sociais, como o Programa Bolsa Família (PBF) e as aposentadorias rurais, que modificaram o salário de reserva dos membros de famílias beneficiárias ${ }^{4}$.

Entretanto, Junior e Bacha (2016), ao verificarem a proporção de pessoas ocupadas em atividades agrícolas e não agrícolas no meio rural do Paraná, constataram que o número de indivíduos empregados em atividades agrícolas na zona rural diminui cerca de 8,9\% entre 2000 e 2010. Para os autores, diversos fatores se relacionaram a essa redução de trabalhadores agrícolas, desde a adoção de tecnologias menos intensivas em trabalho até a redução de investimentos e auxílios governamentais. No entanto, esses fatores não foram aprofundados pelos autores.

Ainda no que se refere ao mercado de trabalho rural, ênfase dada por Junior e Bacha (2016), destaca-se que, no ano de 2013, dos 4 milhões de ocupados no meio rural brasileiro, 59,4\% encontravam-se como empregados sem carteira de trabalho assinada. Quanto à distribuição por macrorregiões, o Norte e o Nordeste apresentaram os maiores percentuais nas taxas de informalidade com média de $77,1 \%$, enquanto o Centro-Oeste apresentou 41,2\%, o Sudeste $45,3 \%$ e o Sul 48,9\%. Em relação aos assalariados rurais, esses se concentravam principalmente nas regiões Nordeste, $34,8 \%$, e Sudeste, 34,4\% (DIEESE, 2014).

Sobre o mercado de trabalho rural, DIEESE (2014) avaliou o desemprego regional. Gandra (2005) estudou os condicionantes da formação do mercado, concluindo que atributos como cor, sexo, idade e etnia foram variáveis determinantes no processo de seleção de trabalhadores e na determinação de salários. Santos et al. (2010), ao analisarem a entrada de homens e mulheres no mercado de trabalho rural brasileiro, verificaram equações de rendimento, com diferenciais por gênero e cor. Além disso,

\footnotetext{
${ }^{4}$ Cabe ressaltar que, para os autores, esses benefícios não causaram uma "preguiça rural", houve, sim, uma elevação dos custos do trabalho no meio rural.
} 
notaram que mulheres beneficiadas pelo Programa Bolsa Família (PBF) tenderam a reduzir sua oferta de trabalho. Já Campolina e Silveira (2008); Junior e Bacha (2016) observaram a inversão em termos de importância da renda do trabalho agrícola em detrimento da renda do trabalho não agrícola.

Como visto por Brito et al. (2018), existe uma heterogeneidade no mercado de trabalho brasileiro, na qual o crescimento regional se caracteriza como um atrativo de mão de obra. Sob a ótica do meio rural, regiões mais mecanizadas tendem a ter mais mão de obra (principalmente trabalhadores com alto capital humano), visto que as oportunidades laborais são maiores. Ademais, mesurando os efeitos do crédito rural sobre o emprego, Silva e Arruda (2019) mostraram que o crédito rural tende a aumentar o volume de emprego na região Norte e Nordeste e diminuir nas regiões mais intensivas em capital. Esses resultados denotam o aprofundamento da heterogeneidade no mercado de trabalho, diante da dependência de regiões menos instrumentalizadas de políticas de crédito para o aumento do emprego.

Todos esses fatores aqui discutidos denotam mudanças que ocorreram ao longo de vários anos no mercado de trabalho (urbano e rural) entre as regiões brasileiras. O processo de modernização e mecanização foi decisivo ${ }^{5}$. Entretanto, essas transformações ocorreram de forma desigual, favorecendo o investimento e a adoção de novas tecnologias nas regiões Sul, Sudeste e Centro-Oeste, bem como dificultando o crédito e o acesso às inovações produtivas nas regiões Norte e Nordeste.

Corroborando os efeitos adversos e persistentes da modernização sobre mercado de trabalho rural, Costa e Vieira Filho (2018) mostraram que a transformação do mercado de trabalho no meio rural acelerou não somente a migração para o meio urbano, mas também os fluxos inversos em regiões brasileiras com agricultura modernizada, aumentando as diferenças e a dualidade entre regiões com um setor agropecuário próspero e outro atrasado. Foi mostrado que o mercado de trabalho se modificou, devido às novas atividades não agrícolas que surgiram no meio rural.

Assim, os estudos que buscam verificar questões relacionadas ao desemprego no meio rural tratam da influência da modernização do setor agropecuário sobre o mercado de trabalho rural, do surgimento de atividades não agrícolas, do diferencial de rendimentos entre trabalhadores rurais e dos impactos advindos da crise econômica. Todos esses fatores contribuíram para o aumento da taxa de desocupação no meio rural e, consequentemente, para a consolidação do desemprego severo.

\footnotetext{
${ }^{5}$ O processo de modernização da agropecuária brasileira iniciou com a implementação do Sistema Nacional de Crédito Rural (SNCR) e da Empresa Brasileira de Pesquisa Agropecuária (EMBRAPA) (Buainain e Dedecca, 2010).
} 


\section{Metodologia}

\subsection{Base de dados para desemprego severo no meio rural}

Procurou-se utilizar dados da PNAD Contínua, para o ano de 2017, realizada pelo IBGE. Ademais, foi realizado um tratamento necessário para o estudo, com o uso do peso do indivíduo na amostra, com o intuito de fazer inferência de resultados na população. O Quadro 1 sintetiza as variáveis adotadas.

As variáveis do modelo foram selecionadas de acordo com a sua importância em relação ao desemprego severo no meio rural do Brasil, bem como na literatura que trata do assunto. Ademais, foram aplicados filtros de seleção, buscando uma amostra homogênea. Selecionaram-se pessoas que na semana de referência da pesquisa estavam a procura de trabalho e que tinham entre 16 e 65 anos de idade. Em seguida, utilizou-se o modelo Probit $^{6}$, no intuito de mensurar a probabilidade de um trabalhador residente no meio rural do Brasil estar na situação de desemprego severo.

A amostra considerada nesta pesquisa é diferente da utilizada por Arruda et al. (2017), que analisou o desemprego severo somente para o Brasil e para as regiões Sul e Sudeste. Neste estudo, são consideradas todas as regiões, bem como uma análise agregada para o Brasil. Outra diferença está no foco do trabalho, em que, especificamente, são verificadas as probabilidades para as zonas rurais, disponibilizando dados atualizados sobre o tema e chamando a atenção para as áreas que mais carecem de políticas públicas.

\subsection{Estatisticas descritivas do desemprego severo}

Na Tabela 1, é apresentada uma síntese das estatísticas descritivas da amostra utilizada na pesquisa. Com relação à variável de pesquisa, percebe-se que, em média, $35 \%$ dos chefes de família estavam desempregados, procurando por trabalho há mais de 1 ano, ou seja, estavam na condição de desemprego severo.

Assim, dos indivíduos desempregados, $31 \%$ são chefes de família, 55\% são homens e 75\% são pessoas não brancas. A idade média dos trabalhadores desempregados era de 31 anos. Desagregando a idade, tem-se que 43\% tinham idade média entre 16 e 25; 25\% entre 26 e 25 anos; 17\% com idade média entre 36 e 45; e 15\% entre 46 e 65 anos de idade. Examinando o nível de instrução dos indivíduos desempregados, cerca de 49\% tinham nivel fundamental incompleto e/ou completo; $41 \%$ nivel médio incompleto e/ou completo; 5\% sem instrução ou analfabeto; e 5\% tinham nível superior.

\footnotetext{
${ }^{6}$ Também foi utilizado o modelo biprobit em uma análise secundária com o intuito de mensurar probabilidades dos níveis educacionais dado que existem beneficiários do PBF e aposentados na família.
} 
Quadro 1. Descrição das variáveis do desemprego severo

\begin{tabular}{|c|c|}
\hline Variável de interesse & Descrição \\
\hline Desemprego severo & $\begin{array}{l}1 \text { - se o indivíduo estiver desempregado mais } 12 \text { meses; } \\
0 \text { - se o indivíduo estiver desempregado até } 12 \text { meses. }\end{array}$ \\
\hline Variáveis & Descrição \\
\hline Masculino & $\begin{array}{l}1 \text { - se o indivíduo for do sexo masculino; } \\
0 \text { - se o indivíduo for do sexo feminino. }\end{array}$ \\
\hline Cor & $\begin{array}{l}1 \text { - se o indivíduo for não branco; } \\
0 \text { - caso contrário. }\end{array}$ \\
\hline Chefe da Família & $\begin{array}{l}1 \text { - se o indivíduo for Chefe da família; } \\
0 \text { - caso contrário. }\end{array}$ \\
\hline Aposentados & $\begin{array}{l}1 \text { - se tem aposentados na família; } \\
0 \text { - caso contrário. }\end{array}$ \\
\hline Programa Bolsa Família & $\begin{array}{l}1 \text { - se a família recebe o Programa Bolsa Família; } \\
0 \text { - caso contrário. }\end{array}$ \\
\hline Sem instrução & $\begin{array}{l}1 \text { - sem instrução e/ou menos de } 1 \text { ano de estudo; } \\
0 \text { - caso contrário. }\end{array}$ \\
\hline Ensino Fundamental & $\begin{array}{l}1 \text { - fundamental incompleto e completo ou equivalente; } \\
0 \text { - caso contrário. }\end{array}$ \\
\hline Ensino Médio & $\begin{array}{l}1 \text { - médio incompleto e completo ou equivalente; } \\
0 \text { - caso contrário. }\end{array}$ \\
\hline Ensino Superior & $\begin{array}{l}1 \text { - superior incompleto e completo ou equivalente; } \\
0 \text { - caso contrário. }\end{array}$ \\
\hline Idade 1 & $\begin{array}{l}1 \text { - se o indivíduo tem entre } 16 \text { e } 25 \text { anos; } \\
0 \text { - caso contrário. }\end{array}$ \\
\hline Idade 2 & $\begin{array}{l}1 \text { - se o indivíduo tem entre } 26 \text { e } 35 \text { anos; } \\
0 \text { - caso contrário. }\end{array}$ \\
\hline Idade 3 & $\begin{array}{l}1 \text { - se o indivíduo tem entre } 36 \text { e } 45 \text { anos; } \\
0 \text { - caso contrário. }\end{array}$ \\
\hline Idade 4 & $\begin{array}{l}1 \text { - se o indivíduo tem entre } 46 \text { e } 65 \text { anos; } \\
0 \text { - caso contrário. }\end{array}$ \\
\hline
\end{tabular}

Fonte: Elaborado pelos autores. 
A renda do não trabalho no meio rural é representada pela aposentadoria rural e pelo Programa Bolsa Família (PBF). Como é apresentado na Tabela 1, verifica-se que $49 \%$ das famílias com desempregados recebem o PBF, enquanto em $24 \%$ dessas famílias existiam pelo menos um aposentado. Essas estatísticas mostram que programas sociais, como o PBF e a previdência rural, têm forte presença nas famílias com integrantes desempregados, denotando um efeito distributivo de renda no meio rural. Além da questão distributiva de renda, (Buainain e Dedecca, 2010) apontam para uma participação cada vez maior da aposentadoria rural na composição da renda familiar.

Tabela 1. Estatísticas descritivas das variáveis do desemprego severo

\begin{tabular}{lrr}
\hline \hline Variáveis & Média & Desvio-Padrão \\
\hline Desemprego Severo & 0,35 & 0,48 \\
Chefe da Família & 0,31 & 0,46 \\
PBF & 0,49 & 0,50 \\
Aposentados na Família & 0,24 & 0,43 \\
Sexo & 0,55 & 0,50 \\
Cor & 0,75 & 0,43 \\
\hline Idade & & \\
\hline Idade & 31 & 11,49 \\
Idade 16 a 25 & 0,43 & 0,49 \\
Idade 26 a 35 & 0,25 & 0,43 \\
Idade 36 a 45 & 0,17 & 0,38 \\
Idade 46 a 65 & 0,15 & 0,35 \\
\hline Instrução & & 0,21 \\
\hline Sem Instrução & 0,05 & 0,50 \\
Fundamental & 0,49 & 0,49 \\
Médio & 0,41 & 0,22 \\
Superior & 0,05 & \\
\hline \hline
\end{tabular}

Fonte: Elaborado pelos autores, a partir dos dados da pesquisa.

\subsection{Modelagem econométrica: modelo Probit}

O modelo de Probit é um modelo de escolha discreta, em que a variável dependente é binária, assumindo $(0 / 1) .{ }^{7}$ Em nossa pesquisa, $(Y=1)$ quando o trabalhador rural está desempregado há mais de um ano e está procurando emprego e $(Y=0)$

\footnotetext{
${ }^{7}$ Ver Greene (2000).
} 
quando o trabalhador rural está desempregado há menos de um ano e está procurando emprego. A estimação é realizada assumindo um vetor de covariadas $X$, que impacta na probabilidade de estar no desemprego severo no mercado de trabalho rural. Então, segue que:

$$
\begin{gathered}
\operatorname{Prob}(Y=1 \mid X)=F(X, \beta) \\
\operatorname{Prob}(Y=0 \mid X)=1-F(X, \beta)
\end{gathered}
$$

O conjunto de parâmetros $\beta$ reflete o impacto de mudanças em $X$ na probabilidade de o trabalhador rural estar no desemprego severo. Assim, a especificação do modelo é dada por:

$$
F(X, \beta)=X^{\prime} \beta
$$

Desde que $E[Y \mid X]=F(X, \beta)$, o modelo de regressão pode ser construído da seguinte forma:

$$
Y=E[Y \mid X]+(1-E[Y \mid X])=X^{\prime} \beta+\epsilon
$$

O modelo Probit utiliza a função de distribuição acumulada (FDA) da normal:

$$
F(X)=\int_{-\infty}^{X_{0}}\left(1 / \sqrt{\left(2 \sigma^{2} \pi\right)} e^{\left.-\left((X-\mu)^{2}\right) /\left(2 \sigma^{2}\right)\right)}\right.
$$

ou seja:

$$
P_{i}=P(Y=1 \mid X)=\int_{-\infty}^{X \beta} \varphi_{t} d t=\phi X_{i} \beta
$$

em que $\varphi($.$) é comumente utilizada para representar uma distribuição normal. Qual-$ quer que seja a distribuição utilizada, é importante notar que os parâmetros do modelo, como os de qualquer modelo de regressão não linear, não são necessariamente os efeitos marginais a que estamos acostumados a analisar. Em geral, tem-se que:

$$
\partial E[Y \mid X] / \partial X=\left[d F\left(X^{\prime} \beta\right) / d\left(X^{\prime} \beta\right)\right] \beta=f\left(X^{\prime} \beta\right) \beta
$$

em que $f($.$) é a função de densidade relativa à distribuição acumulada, F($.$) . Para a$ distribuição normal, esse resultado é: 


$$
\partial E[Y \mid X] / \partial X=\varnothing\left(X^{\prime} \beta\right) \beta
$$

em que $\varnothing(t)$ é a densidade normal padrão. Para calcular os efeitos marginais, pode-se avaliar as expressões nas médias amostrais ou avaliar os efeitos marginais em cada observação e usar a média amostral dos efeitos marginais individuais.

\section{Análise dos resultados}

\subsection{Resultados da estimação do modelo de desemprego severo}

Fazendo uso do modelo Probit, a Tabela 2 apresenta os coeficientes das probabilidades de ocorrência do desemprego severo no meio rural do Brasil e de suas regiões, dadas as covariadas utilizadas. Os modelos foram estimados com erros-padrões baseados na variância robusta. Ademais, a estatística de Wald e o teste de Razão de Verossimilhança foram significativos a 1\%, indicando que as variáveis utilizadas são conjuntamente significantes. Com relação às observações das amostras, a região Nordeste apresentou o maior contingente de desempregados no país.

A Tabela Al no apêndice apresenta o número de desempregados no Brasil rural em 2017 , que era de aproximadamente 1.249 .934 , sendo que $35,12 \%$ desses desempregados se encontravam na condição de desemprego severo. Em relação às estimações, a maioria das variáveis foi significante ao nível de 1\%, excetuando-se para quando o desempregado tem entre 36 e 45 anos de idade. Além disso, quando o indivíduo tem entre 16 e 25 anos de idade, a significância estatística é de 10\%.

As variáveis chefes de família, homens, não brancos e faixa de idade entre 16 a 35 anos diminuem a probabilidade de estar no desemprego severo. Esse resultado, para as zonas rurais brasileiras, em relação ao chefe de família, corrobora os trabalhos aplicados para o Brasil, sem o corte da área rural, realizados por Menezes-Filho e Picchetti (2000); Arruda et al. (2017).

Com relação ao gênero, ser homem diminui as chances de o trabalhador rural encontrar-se no desemprego severo. Em relação à cor do trabalhador, há menor probabilidade de uma pessoa branca pertencer ao desemprego severo. Resultados para essas variáveis se diferenciam dos encontrados por Arruda et al. (2017) ${ }^{8}$. Uma possível explicação para a diferença nos sinais é a maior participação de homens e de pessoas não brancas no mercado de trabalho rural.

\footnotetext{
${ }^{8}$ Cabe ressaltar que, nesta pesquisa, a referência foi o trabalhador branco, enquanto, no trabalho supracitado, considerou-se como referência o trabalhador negro.
} 
Tabela 2. Probabilidade e efeito marginal do desemprego severo para o Brasil rural

\begin{tabular}{|c|c|c|}
\hline Variáveis & Coeficientes & $\begin{array}{r}\text { Efeitos } \\
\text { Marginais }\end{array}$ \\
\hline \multirow[t]{2}{*}{ Pbffam } & $0,00682^{* * *}$ & $0,00251^{* * *}$ \\
\hline & $(0,00247)$ & $(0,000910)$ \\
\hline \multirow[t]{2}{*}{ Aposentadosfam } & $0,0522^{* * *}$ & $0,0193^{* * *}$ \\
\hline & $(0,00289)$ & $(0,00108)$ \\
\hline \multirow[t]{2}{*}{ chefefamilia_ } & $-0,224^{* * *}$ & $-0,0808^{* * *}$ \\
\hline & $(0,00301)$ & $(0,00106)$ \\
\hline \multirow[t]{2}{*}{ Sexo } & $-0,458^{* * *}$ & $-0,169 * * *$ \\
\hline & $(0,00246)$ & $(0,000901)$ \\
\hline \multirow[t]{2}{*}{ Cor } & $-0,00459^{*}$ & $-0,00169 *$ \\
\hline & $(0,00276)$ & $(0,00102)$ \\
\hline \multirow[t]{2}{*}{ idade_1 } & $-0,0130 * * *$ & $-0,00479 * * *$ \\
\hline & $(0,00428)$ & $(0,00158)$ \\
\hline \multirow[t]{2}{*}{ idade_2 } & $-0,0404^{* * *}$ & $-0,0148^{* * *}$ \\
\hline & $(0,00423)$ & $(0,00155)$ \\
\hline \multirow[t]{2}{*}{ idade_3 } & 0,0022 & 0,000813 \\
\hline & $(0,00431)$ & $(0,00159)$ \\
\hline \multirow[t]{2}{*}{ Sem_instrulano } & $0,104^{* * *}$ & $0,0390 * * *$ \\
\hline & $(0,00812)$ & $(0,00309)$ \\
\hline \multirow[t]{2}{*}{ Educfundamental } & $0,111^{* * *}$ & $0,0410^{* * *}$ \\
\hline & $(0,00573)$ & $(0,00211)$ \\
\hline \multirow[t]{2}{*}{ Educmedio } & $0,195^{* * *}$ & $0,0722^{* * *}$ \\
\hline & $(0,00560)$ & $(0,00208)$ \\
\hline \multirow[t]{2}{*}{ Constante } & $-0,213^{* * *}$ & \\
\hline & $(0,00671)$ & \\
\hline Número de observações & & $1.249,93$ \\
\hline Wald chi2(11) & & 56170,41 \\
\hline Prob >chi2 & & 0,00000 \\
\hline Log pseudolikelihood & & $-781878,02$ \\
\hline Pseudo R2 & & 0,0349 \\
\hline
\end{tabular}

Nota: Erros-padrão robustos em parênteses.

*** $\mathrm{p}<0,01 ;{ }^{* *} \mathrm{p}<0,05 ;{ }^{*} \mathrm{p}<0,1$.

Fonte: Elaborado pelos autores, a partir dos dados da pesquisa. 
No mercado de trabalho, a idade pode ser considerada como uma proxy de experiência. Desse modo, foi utilizada como referência a faixa entre 46 e 65 anos de idade. Assim, jovens entre 16 e 35 anos de idade diminuem a probabilidade de desemprego severo, dada a faixa de referência. Entretanto, trabalhadores com idade entre 36 e 45 anos, não há probabilidade de participar do desemprego severo, dado que a estimativa para essa faixa não foi estatisticamente significante. Esse resultado diferencia-se do encontrado para o trabalhador brasileiro em geral em Arruda et al. (2017).

Segundo Mincer (1974), quanto maior o nivel educacional, maiores os ganhos dos trabalhadores. Entretanto, os trabalhadores ofertavam trabalho de acordo com seus salários de reserva, que eram correlacionados positivamente com o nível educacional. Assim, trabalhadores com nível superior se mostram como referência para essa análise, apesar de que no meio rural grande parte dos indivíduos têm menor nível educacional. Nesse sentido, não ter instrução ou menos de um ano e/ou ter nível fundamental completo e/ou médio completo atuam de forma a aumentar a probabilidade da ocorrência do desemprego severo no mercado de trabalho rural do Brasil. A maior probabilidade é para o trabalhador com ensino médio. Esse resultado é interessante, pois, no meio rural, a maioria das atividades ocupacionais não exige um nível de educação elevado.

Os resultados também apontam que, caso a família tenha aposentados, há uma maior chance de ter trabalhadores em situação de desemprego severo na família. Em relação aos programas sociais, como o PBF e aposentadorias rurais, Buainain e Dedecca (2010) mostram que houve uma modificação da relação de trabalho no meio rural, devido à estabilidade econômica da família, principalmente em relação aos trabalhos temporários, o que pode levar o trabalhador a substituir a renda do trabalho pela renda do não trabalho.

Verificou-se também que a probabilidade de estar no desemprego severo aumenta quando a família recebe o PBF, apesar de ser próximo de zero. Essa análise busca entender o comportamento dos trabalhadores, em relação à procura por emprego, dado que os resultados encontrados mostram que o PBF gera um possivel desincentivo ao trabalho, como apresentado nos artigos de Tavares (2010); Cavalcanti et al. (2016); Costa et al. (2018). Esse resultado mostra que o trabalhador está à procura de emprego há mais de 12 meses, mas não está trabalhando. O desempregado, nesse caso, está interessado no salário de reserva, ou seja, dado que a família tem uma renda via PBF, procura-se por emprego com maior remuneração, trocando a renda do trabalho pela renda do não trabalho, o que é denominado por Tavares (2010) de efeito renda ${ }^{9}$.

Os resultados apresentados nos parágrafos anteriores mostraram as chances a favor das variáveis utilizadas no modelo, sobre a probabilidade de trabalhadores se encontrarem no desemprego severo no meio rural do Brasil. Entretanto, faz-se necessário verificar a probabilidade desses efeitos, para se ter uma melhor compreensão do

\footnotetext{
${ }^{9}$ Segundo Tavares (2010), há uma redução da oferta de trabalho, ocasionada pelo aumento da renda da família do não trabalho, por ser beneficiária do PBF.
} 
comportamento das variáveis sobre a probabilidade do desemprego severo.

Conforme os efeitos marginais, observa-se que, em relação à idade, a probabilidade de os trabalhadores com idade entre 16 e 25 ficarem desempregados mais de 12 meses é muito pequena e próxima de zero, denotando que no meio rural os jovens com pouca experiência têm menores chances de ficarem no desemprego severo. Uma causa para tal resultado é que possivelmente o salário de reserva desses jovens não é alto, devido ao baixo capital humano nessas áreas. Em relação aos trabalhadores desempregados com idade entre 26 e 35 anos, a probabilidade de permanecerem no desemprego severo é aproximadamente 1,48\% menor do que de trabalhadores com idade de 46 e 65 anos. Trabalhadores na a faixa de idade entre 36 e 45 anos não têm probabilidade de estar no desemprego severo.

Os efeitos marginais, para o nivel educacional, mostram que, no meio rural, mesmo com todas as faixas educacionais aumentando as chances de o trabalhador estar no desemprego severo, verifica-se que, quanto menor o nível educacional, menor essa probabilidade. Isto é, ter o ensino médio completo aumenta a probabilidade de o trabalhador ocorrer no desemprego severo em 7,22\%, com ensino fundamental aumenta $4,10 \%$ e trabalhadores sem instrução ou 1 ano de estudo aumenta a probabilidade do desemprego severo em $3,90 \%$.

A probabilidade de trabalhadores do sexo masculino estarem no desemprego severo diminui $16,90 \%$ quando comparada à das mulheres. Além disso, com relação ao gênero ser branco, tem-se uma diminuição da probabilidade do emprego severo. Ser chefe de família diminui as chances do desemprego severo em 8,08\%. Em relação à cor do trabalhador, ser não branco diminui a probabilidade do desemprego severo, entretanto, a estimativa é próxima de zero.

Em relação aos programas sociais, quando existem aposentados na família, a probabilidade do desemprego severo aumenta quando a família possui componentes que recebem o programa, mas esse efeito é pequeno. O maior impacto é com relação a aposentados, que aumenta a probabilidade do desemprego severo em cerca de 1,93\%, indicando uma relação positiva de aposentadoria no meio rural e o indivíduo passar desempregado mais de 12 meses.

Conforme apresentado na Tabela A1 no apêndice, a região Nordeste possui o maior número de desempregados no meio rural, entre as regiões brasileiras, com 754.672 trabalhadores nessa condição, sendo que destes 281.139 se encontravam na condição de desemprego severo. A região Centro-Oeste possui o menor número de desempregados e de ocorrência do desemprego severo. O total de desempregados pode ser explicado pelas atividades rurais distintas nessas regiões. O mercado de trabalhado do meio rural nordestino é em sua maioria formando pela agricultura familiar, com exceção da região do Matopiba ${ }^{10}$. O agronegócio brasileiro está concentrado na região

\footnotetext{
${ }^{10}$ Englobando o cerrado nordestino, a região do Matopiba é formada por todo o estado do Tocantins e parte dos estados da Bahia, do Maranhão e do Piauí. Conforme Buainain e Dedecca (2010), o crescimento
} 
Centro-Oeste, apresentando maiores oportunidades aos trabalhadores rurais.

A Tabela 3 apresenta as estimativas da probabilidade de estar no desemprego severo, bem como o efeito marginal dos trabalhadores rurais nas regiões brasileiras. Como se verifica, os sinais, tanto para as estimativas de chances a favor quanto para os efeitos marginais dos determinantes do desemprego severo no meio rural, variam de acordo com a região analisada, denotando heterogeneidade nos mercados de trabalhos no meio rural brasileiro. Ou seja, mesmo no meio rural, o mercado de trabalho se diferencia bastante, principalmente em regiões onde há predominância da agricultura familiar ou onde o agronegócio tem maior presença e é bastante heterogêneo. Esses resultados corroboram a literatura que evidencia a heterogeneidade no meio rural brasileiro.

No que se refere aos resultados nas distintas regiões, a aposentadoria rural e o PBF apresentaram probabilidades negativas nas regiões Sudeste e Centro-Oeste e não houve mudança do desemprego severo para a região Sul em relação ao PBF, indicando que a transferência de renda e a aposentadoria rural contribuíram para uma diminuição desse tipo de desemprego. Assim, para essas regiões, o efeito se diferencia dos encontrados para o Brasil e para as demais regiões, identificando um meio rural mais dinamizado. Nesse sentido, como observado por (Staduto et al., 2004), o mercado de trabalho rural acompanha as diferenças de tecnologia entre as regiões. Assim, onde houve um maior processo de modernização, as chances do desemprego severo diminuem. No entanto, nas regiões onde a pobreza é mais elevada, tais como Norte e Nordeste, o PBF funciona de forma a desestimular o emprego. Deve-se ressaltar que o PBF atua na mitigação da pobreza e, assim como apresentado por Carrets et al. (2019); Tavares (2010), pode estimular a redução do trabalho em condições mais precárias.

Em relação à cor do indivíduo, nas regiões onde existe produção direcionada para o agronegócio e a agricultura familiar é mais mecanizada, Sul e Centro-Oeste do Brasil, respectivamente, para trabalhadores não brancos, nessas regiões, a probabilidade de desemprego severo aumenta, ou seja, nessas regiões, há discriminação racial que contribui para o diferencial de empregabilidade, corroborando novamente a literatura sobre diferenciais de rendimentos entre a cor dos trabalhadores.

Em todas as regiões, ser chefe de família ou do sexo masculino diminui a probabilidade de o trabalhador estar desempregado há mais 12 meses, resultados também encontrados por Arruda et al. $(2016,2017)$ para as regiões Sul e Sudeste. Na região Nordeste, no que tange a ser chefe de família, o efeito marginal é maior, comparativamente às demais regiões, cerca de 10,1\%. Esse resultado é interessante, visto que a maioria dos trabalhadores que se encontram no desemprego severo está nessa região. Para o trabalhador rural da região Centro-Oeste, ser do sexo masculino tem um impacto negativo de $32,9 \%$. Esse resultado já era esperado devido ao dinamismo dessa

agrícola dessa região proporciona geração de empregos e renda locais no meio rural. 
região. Em relação à cor do trabalhador, para as regiões Norte com efeito marginal de 1,19\%; Nordeste, 4,75\%; e Sudeste, próximo de zero, ser não branco diminui a probabilidade da ocorrência de desemprego severo, quando comparado aos brancos. Para as regiões Sul e Centro-Oeste, ser branco aumenta a probabilidade em 13,3\% e $12,7 \%$, respectivamente. Em relação às faixas etárias, nas regiões Norte e Sudeste, ter idade entre 16 e 25 anos aumenta a probabilidade de desemprego severo, quando comparada a de trabalhadores na faixa de 46 a 65 anos de idade. Na região Norte, a probabilidade de o trabalhador nessa idade ficar desempregado mais de 12 meses é 1,96\%, já na região Sudeste é de 5,48\%. Nas outras regiões, essa faixa de idade diminui as chances a favor e, consequentemente, seus efeitos marginais. Desempregados com idade entre 26 e 35 anos têm menos chances de estarem no desemprego severo para a maioria das regiões, excetuando-se a região Centro-Oeste, onde as chances a favor são positivas, e a região Norte, na qual não há probabilidade de estar desempregado a mais de 12 meses. Para indivíduos entre 26 e 35 anos de idade, que estão desempregados no meio rural das regiões Nordeste, Sul e Centro-Oeste, diminui-se a probabilidade da ocorrência do desemprego severo. Para as outras regiões, essa faixa de idade aumenta a probabilidade de o trabalhador rural estar no desemprego severo, quando comparada a de trabalhadores com 46 a 65 anos de idade.

Em relação às faixas de educação, têm-se que, nas regiões Sudeste e Centro-Oeste, não ter instrução ou ter menos de um ano de instrução aumenta a probabilidade do desemprego severo, sendo que, nas outras regiões, há uma diminuição na probabilidade. Esses resultados apontam para uma relação positiva entre regiões mais dinamizadas e acumulação de capital humano. Para trabalhadores desempregados com ensino fundamental, ser da região Nordeste, Sul e Centro-Oeste aumenta a probabilidade da ocorrência do desemprego severo. Quando se analisam trabalhadores desempregados com ensino médio, em todas as regiões, tem-se a diminuição da probabilidade de ocorrência do desemprego severo. Esse fato não é observado na região Nordeste, quando comparado a trabalhadores desempregados com nível superior.

Portanto, as estimativas do desemprego severo por região sinalizam a forte heterogeneidade regional no mercado de trabalho rural, tendo as regiões Sul, Sudeste e Centro Oestes com menores ocorrências desse tipo de desemprego, enquanto o Norte e Nordeste obtêm as maiores probabilidades. Essas estimativas desses determinantes corroboram o processo de modernização assimétrico ocorrido no meio rural brasileiro, em que regiões mais capitalizadas têm mais oportunidades de emprego.

\subsection{Probabilidades associadas às variáveis educacionais para o Brasil e regiões}

Nesta subseção, será analisada a interação entre o perfil educacional e as variáveis de previdência social (aposentados na família) e do PBF. Busca-se obter, assim, estimativas referentes à probabilidade conjunta do nível educacional dos trabalhadores rurais terem algum membro da família beneficiário do PBF ou de benefícios 
previdenciários e estarem em condições de desemprego severo. De um lado, o nível educacional é um dos principais determinantes no acesso ao PBF. De outro lado, ter aposentados na família pode influenciar o trabalhador a se encontrar nessa condição de desemprego. A Tabela 3 mostra os efeitos marginais das possiveis ocorrências.

Como se verifica, no Brasil, aposentados na família aumentam a probabilidade de o trabalhador rural ocorrer no desemprego severo, à medida que o grau de escolaridade aumenta. Por exemplo, não ter instrução ou apenas 1 ano de instrução diminui a probabilidade e ter ensino fundamental e médio aumenta essa probabilidade em 0,08\% e em 1,79\%, respetivamente, apesar de os efeitos marginais serem muito próximos de zero.

Em termos regionais, em todos os níveis educacionais, se o trabalhador estiver em áreas rurais do Nordeste e do Sudeste, as probabilidades de estar na condição de desemprego severo, dado que pertence a uma família com aposentados, aumentam. Isso também ocorre em todas as categorias de escolaridade, sendo que, na região Nordeste, a probabilidade tem mais efeito caso o trabalhador rural tenha niveis educacionais mais elevados. O oposto ocorre no Sudeste, com maiores efeitos marginais em todos os níveis. No Sul e Centro-Oeste, ter aposentados na família diminui a probabilidade de o trabalhador rural estar em condições de desemprego severo em todos os níveis de educação, denotando que, nas regiões onde o agronegócio é mais intenso, o nivel educacional afeta negativamente o trabalhador rural estar por mais de doze meses desempregado nas regiões com aposentados no domicílio.

Analisando as probabilidades dos niveis educacionais do trabalhador rural sobre a presença no desemprego severo, dado que se têm beneficiários do PBF na família, temse que, para o Brasil e para todas as regiões, excetuando-se o nível sem instrução ou 1 ano de instrução do Norte, a probabilidade aumenta. Esses resultados indicam que, por exemplo, não ter instrução ou apenas 1 ano de instrução aumenta a probabilidade em $15,26 \%, 10,37 \%, 27,31 \%, 2,63 \%$ e $12,82 \%$ do trabalhador rural estar desempregado por mais de doze meses, dado que faz parte de uma família beneficiária do PBF, no Brasil e nas regiões Nordeste, Sudeste, Sul e Centro-oeste, respectivamente. Essas probabilidades indicam um maior efeito para a região Sudeste, mesmo com a região Nordeste tendo o maior número de trabalhadores em condições de desemprego severo.

Possuir ensino médio aumenta a probabilidade em 12,79\%, 2,03\%, 11,24\%, 9, 10\%, $6,88 \%$ de o trabalhador rural estar em condições de desemprego, dado que algum membro da família é beneficiário do PBF, para o Brasil e para as regiões Norte, Nordeste, Sudeste, Sul e Centro-Oeste, respectivamente. Deve-se ressaltar que para o Nordeste a probabilidade é maior, 11,24\%, quanto maior for a categoria de educação. Isto é, quanto maior o nível educacional, aumentam-se as chances da ocorrência do desemprego severo no Nordeste brasileiro. Esse resultado em particular corrobora as estimativas encontradas na subseção anterior. 


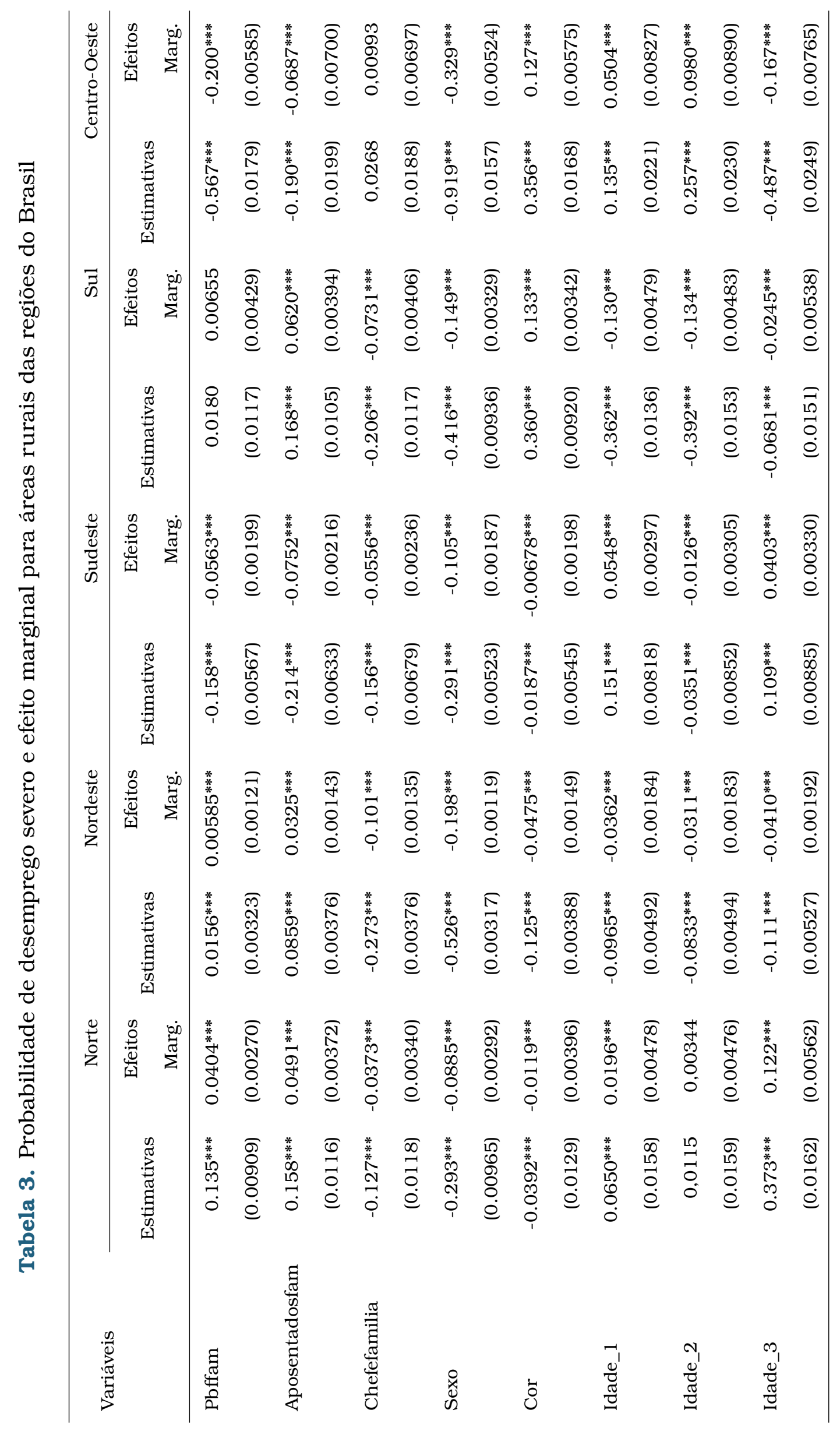




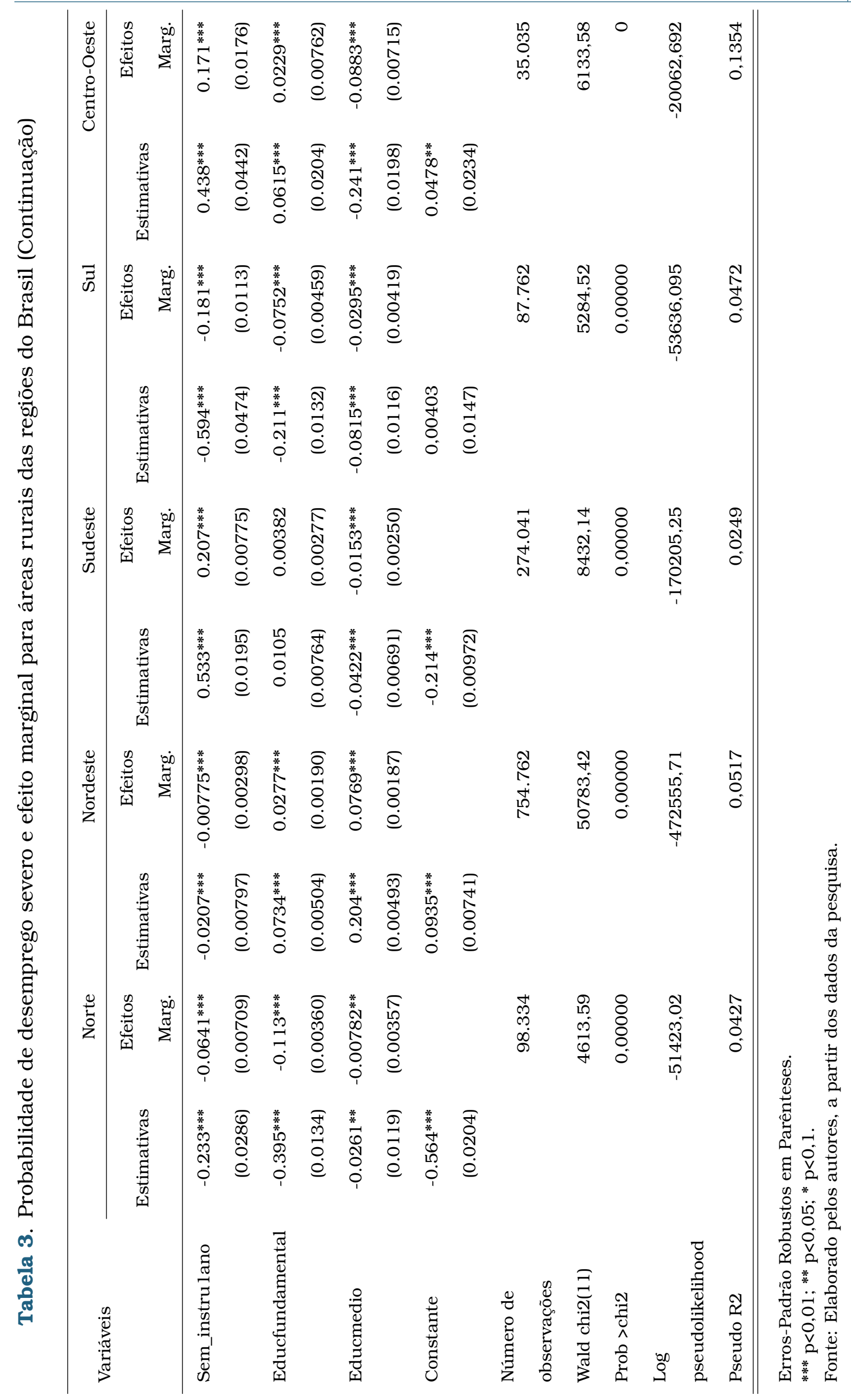




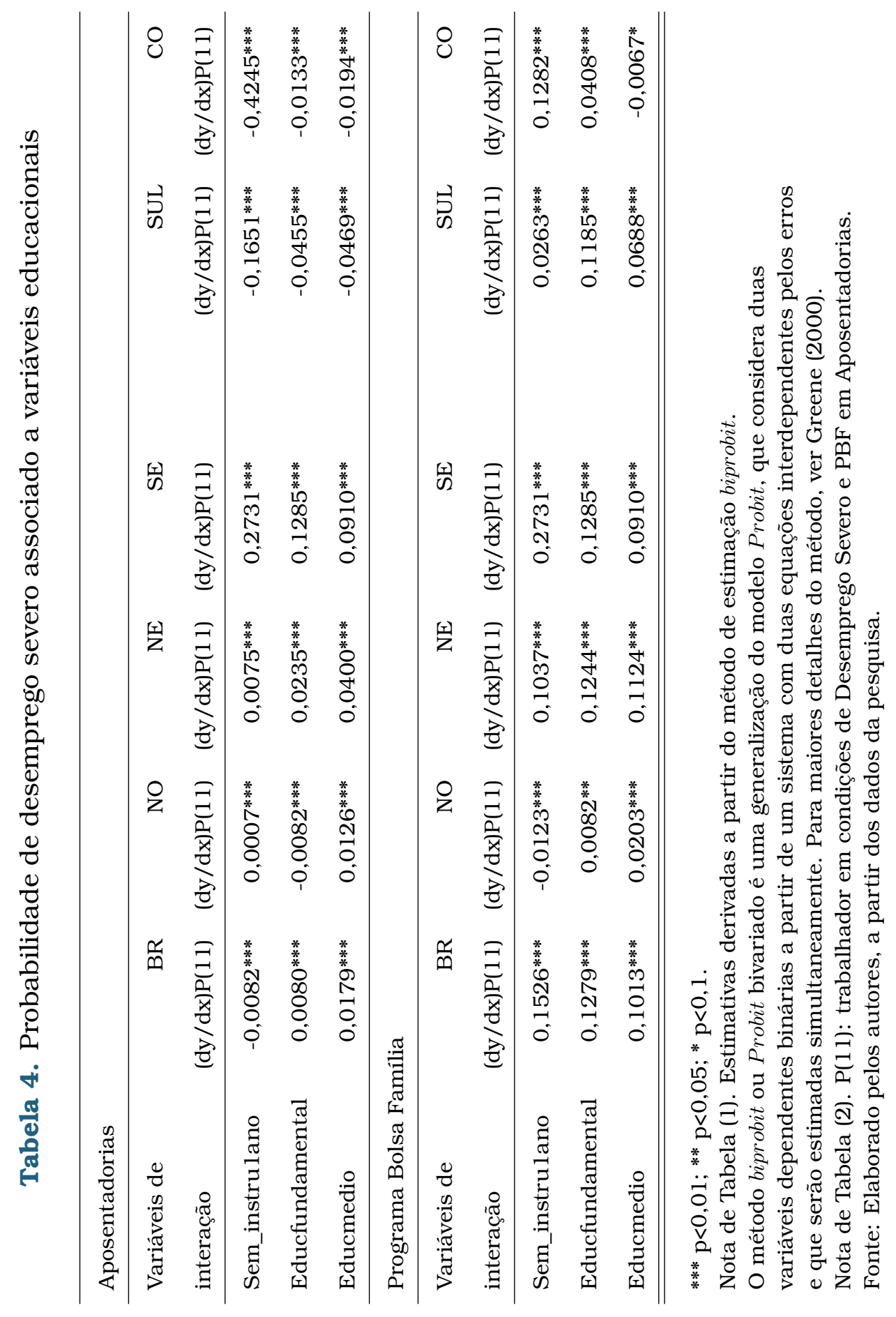




\section{Considerações finais}

Este estudo mensurou as probabilidades e o impacto da ocorrência do desemprego severo no meio rural do Brasil e das regiões, por meio do modelo Probit. Para tanto, utilizou-se uma amostra retirada da PNAD do ano de 2017, auge da crise do emprego no País.

No âmbito geral, os resultados apontaram, por um lado, que dos desempregados em que algum membro da família recebia o PBF, auferia benefício da aposentadoria, não tinha instrução, ensino fundamental e/ou ensino médio, comparados aos desempregados com ensino superior, aumentava-se a probabilidade de o trabalhador ficar desempregado mais de 12 meses. Por outro lado, ser chefe de família, homem, da cor não branca e ter idade entre 16 e 25 anos e 26 e 45 anos foram características estudadas que diminuíam a probabilidade da ocorrência do desemprego severo. Para trabalhadores desempregados na faixa de idade de 26 a 35 anos, não foi significante.

No escopo regional, os resultados em maior parte seguiram os obtidos para o âmbito nacional. No entanto, existem dois resultados que chamaram a atenção. Ao contrário do resto do país, o PBF e a aposentadoria exercem influência ao diminuir o desemprego severo no Sudeste e na região Centro-Oeste, excetuando-se a região Sul no PBF, onde não há probabilidade de o trabalhador rural estar desempregado por mais de 12 meses. Assim, indica-se que a política de transferência de renda e o benefício da aposentadoria contribuíram para minimizar o desemprego severo nessas regiões. Vale ressaltar que o Centro-Oeste é a região mais próspera e, portanto, menos dependente de políticas assistencialistas, com condições de trabalho mais dignas. Além disso, as regiões Sudeste e Sul são mais dinâmicas no agronegócio e na agricultura familiar.

No que se refere à questão racial, a cor não branca no Sul e Centro-oeste do País aumentou a probabilidade da ocorrência do desemprego severo. Deve-se lembrar que principalmente na região Sul a colonização histórica se difundiu por uma população branca, denotando que a discriminação racial deve ter influenciado os resultados. Em termos regionais, no que tange às demais variáveis, com raras modificações nos sinais, houve uma grande heterogeneidade no mercado de trabalho rural, principalmente entre as regiões Nordeste, onde a agricultura familiar é preponderante, e Centro-Oeste, em que se observa o predomínio do agronegócio de maior escala produtiva.

Nesse sentido, a partir dos resultados obtidos, procurou-se contribuir para o debate sobre a mitigação do desemprego no mercado de trabalho rural brasileiro, apresentando um diagnóstico econômico que possa subsidiar a formulação de políticas públicas. Os resultados auxiliam o melhor entendimento da relação de políticas de transferência de renda e de questões estruturais como o aumento do desemprego no país.

Assim, é importante criar instrumentos que aumentem a acumulação de capital 
humano nas regiões onde a produção é menos dinamizada, expandindo o crescimento autônomo do agronegócio nas regiões que concentram a extrema pobreza, como já ocorre no cerrado do Norte e Nordeste, ou mesmo nas regiões irrigadas do Semiárido. Esses instrumentos podem ocorrer por meio de outras políticas públicas já existentes, que possam dialogar, por exemplo, com o PBF na contratação de jovens aprendizes e no investimento em capital humano a médio prazo nessas regiões.

Além disso, como verificado na literatura e nesta pesquisa, o crédito rural é fomentador de emprego nas regiões mais vulneráveis. As políticas de crédito, como Pronaf, bem como FNO e FNE, devem atender as especificidades regionais do Norte e Nordeste. Portanto, a lacuna institucional existente no mercado de trabalho pode ser mitigada nas regiões mais carentes, diminuindo a migração por oportunidades laborais e resultando em externalidades positivas. Assim, é possível reduzir as taxas do desemprego severo no meio rural em todo o território nacional.

\section{Referências}

Allegretto, S. e Lynch, D. (2010). The composition of the unemployed and long-term unemployed in tough labor markets. Monthly Labor Review, 133:3.

Araujo, J. A. e Vieira Filho, J. E. R. (2018). Análise dos impactos do Pronaf na agricultura do Brasil no período de 2007 a 2016. Texto para Discussão n. 2412, Instituto de Pesquisa Econômica Aplicada (Ipea).

Arruda, E. F., Guimarães, D. B., e Castelar, I. (2016). Desemprego severo no Nordeste Brasileiro: uma análise para 2003 e 2013. Revista Econômica do Nordeste, 47(1):101-116.

Arruda, E. F., Guimarães, D. B., e Castelar, I. (2017). Uma análise do desemprego severo nas regiões Sul e Sudeste do Brasil em 2013. Planejamento e Políticas Públicas, (48).

Balsadi, O. V. (2001). Mudanças no meio rural e desafios para o desenvolvimento sustentável. São Paulo em Perspectiva, 15(1):155-165.

Barbosa Filho, F. d. H. e Moura, R. L. d. (2015). Evolução recente da informalidade do emprego no Brasil: uma análise segundo as características da oferta de trabalho e o setor. Planejamento e Políticas Públicas, (48).

Brito, J. W. A., Gonçalves, E., e Taveira, J. G. (2018). Externalidades do mercado de trabalho e crescimento regional no Brasil (1996-2008). Revista Brasileira de Estudos Regionais e Urbanos, 12(2):261-276.

Buainain, A. M. e Dedecca, C. S. (2010). Mudanças e reiteração da heterogeneidade do mercado de trabalho agrícola. In: A agricultura brasileira: desempenho recente, desafios e perspectivas. Brasília, DF: Ipea: Mapa. 
Buainain, A. M. e Salvadori D, C. (2009). Emprego e trabalho na agricultura agricultura brasileira. Number IICA E50-969. IICA, Brasília, DF (Brasil).

Bustos, P., Caprettini, B., e Ponticelli, J. (2016). Agricultural productivity and structural transformation: Evidence from Brazil. American Economic Review, 106(6):132065.

Campolina, B. e Silveira, F. G. (2008). O mercado de trabalho rural: evolução recente, composição da renda e dimensão regional. Texto para Discussão n. 1398, Instituto de Pesquisa Econômica Aplicada (Ipea).

Carrets, F. D., Ribeiro, F. G., e da Silva Teixeira, G. (2019). Isolated illiteracy and access to social programs: evidence from Brazil. International Journal of Social Economics, 46(5):669-685.

Cavalcanti, D., Costa, E., Silva, J. L., e Sampaio, R. M. (2016). Impactos do programa bolsa família na renda e na oferta de trabalho das famílias pobres: uma abordagem usando o efeito quantílico de tratamento. Economia Aplicada, 20(2):173-201.

Costa, E. M. e Vieira Filho, J. E. R. (2018). Choque de oferta no crédito rural e seu impacto produtivo na agricultura brasileira. In: Políticas públicas: avaliando mais de meio trilhão de reais em gastos públicos, volume 1, Página 207-224. Brasília: Ipea.

Costa, J. S. e Cunha, M. S. (2010). Determinates do desemprego no Brasil no período de 1981 a 2005: uma análise enfatizando a qualificação do indivíduo em um contexto de maior abertura comercial. Análise Econômica, 28(53):197-220.

Costa, R. A., Costa, E. M., Mariano, F. Z., e Cavalcanti, D. M. (2018). Impactos do Programa Bolsa Família no mercado de trabalho e na renda dos trabalhadores rurais. Nova Economia, 28(2):385-416.

DIEESE (2014). O mercado de trabalho assalariado rural brasileiro.

Diniz, B. P. C. e Silveira, F. G. (2008). Perfis dos rendimentos e dos orçamentos familiares brasileiros: o que diferencia o rural. Texto para Discussão n. 656, Instituto de Pesquisa Econômica Aplicada (Ipea).

Ehrenberg, R. G. e Smith, R. S. (2016). Modern labor economics: Theory and public policy. Routledge.

Gandra, R. M. (2005). O debate sobre a desigualdade de renda no Brasil: da controvérsia dos anos 70 ao pensamento hegemônico nos anos 90. História Econômica \& História de Empresas, 8(1).

Greene, W. H. (2000). Econometric analysis. New Jersey: Prentice Hall.

IBGE (2013). Pesquisa Nacional por Amostra de Domicílios (PNAD). Instituto Brasileiro de Geografia e Estatística. 
IBGE (2017a). Indicadores de Contas Nacionais. Instituto Brasileiro de Geografia e Estatística.

IBGE (2017b). Pesquisa Nacional por Amostra de Domicílios (PNAD). Instituto Brasileiro de Geografia e Estatística.

Junior, G. C. e Bacha, C. J. C. (2016). Análise do pessoal ocupado no meio rural do Paraná de 2000 a 2010. Pesquisa \& Debate, 27(1):385-416.

Long, C. D. (1953). Impact of effective demand on the labor supply. The American Economic Review, 43(2):458-467.

Maia, A. G. e Sakamoto, C. S. (2014). A nova configuração do mercado de trabalho agrícola brasileiro. In: O mundo rural no Brasil do século 21, Página 591-620.

Mariano, F. Z., Costa, E. M., Guimarães, D. B., e Sousa, D. T. d. (2018). Diferenciais de rendimentos entre raças e gêneros, nas regiões metropolitanas, por níveis ocupacionais: uma análise através do pareamento de ñopo. Estudos Econômicos, 48(1):137-173.

Mayer, G. (2014). Increased supply of underutilized labor from 2006 to 2014. Monthly Laboratoty Review, 137:1.

Menezes-Filho, N. A. e Picchetti, P. (2000). Os determinantes da duração do desemprego em São Paulo. Pesquisa e Planejamento Econômico, 30:10-45.

Mincer, J. (1974). Schooling, experience, and earnings. Human Behavior \& Social Institutions, 2:192-215.

Pereira, R. M., Galvão, M. C., e Maxir, H. d. S. (2018). Determinantes do emprego secundário e informalidade: evidências adicionais para o mercado de trabalho brasileiro. Revista Brasileira de Estudos de População, 35(3):419-435.

Ramos, L. (2007). O desempenho recente do mercado de trabalho brasileiro: tendências, fatos estilizados e padrões espaciais. Texto para Discussão n. 1255, Instituto de Pesquisa Econômica Aplicada (Ipea).

Santos, G. C., Fontes, R. M. O., Bastos, P., e Lima, J. E. (2010). Mercado de trabalho e rendimento no meio rural brasileiro. Economia Aplicada, 14(3):355-379.

Silva, J. P. R. e Arruda, E. F. (2019). Impactos do crédito rural no mercado de trabalho da agropecuária dos estados brasileiros. Revista Brasileira de Estudos Regionais $e$ Urbanos, 13(3):340-356.

Staduto, J. A. R., Bacchi, M. R. P., e Bacha, C. J. C. (2004). Avaliação do diferencial de salários na agropecuária brasileira: período de 1966 a 2002. Revista Brasileira de Economia, 58(2):267-295.

Tafner, P. S. B. (2006). Brasil: o estado de uma nação. Instituto de Pesquisa Econômica Aplicada (Ipea). 
Tavares, P. A. (2010). Efeito do Programa Bolsa Família sobre a oferta de trabalho das mães. Economia e Sociedade, 19(3):613-635.

(G) Este artigo está licenciado com uma CC BY 4.0 license.

\section{Apêndice}

\section{Apêndice A. Desemprego severo no meio rural}

Tabela A1. Desempregados no Brasil rural e regiões em 2017

\begin{tabular}{lrrr}
\hline \hline Regiões & Desempregados & Desemprego Severo & Percentual \\
\hline Norte & 98.334 & 23.193 & 0,236 \\
Nordeste & 754.762 & 281.139 & 0,372 \\
Sudeste & 274.041 & 91.515 & 0,334 \\
Sul & 87.762 & 29.894 & 0,341 \\
Centro-Oeste & 35.035 & 13.192 & 0,377 \\
\hline Brasil & 1.249 .934 & 438.933 & 0,351 \\
\hline \hline
\end{tabular}

Fonte: Elaborado pelos autores, a partir dos dados da pesquisa. 